\title{
Firm-Sponsored General Training in a Frictionless Labor Market
}

\author{
Felipe Balmaceda ${ }^{1}$ \\ Ilades-Georgetown University \\ Economics Department ${ }^{2}$
}

First Draft: October 30, 1998

November 26, 2001

${ }^{1}$ I would like to express my gratitude to Eduardo Saavedra, Felipe Zurita and Central Bank of Chile regular seminar participants for their useful comments. Special thanks go to Alex Galetovic for carefully reading the paper and his insightful comments.

${ }^{2}$ Erasmo Escala 1835, Zip Code 6500620, Santiago-Chile. E-mail: fbalmace@uahurtado.cl, http://www.ilades.cl/economia/profe.htm 


\begin{abstract}
In this paper I show that, contrary to Becker's (1962) Human Capital theory and consistent with the evidence, in a frictionless labor market model firms pay for general training, while the worker receives the full return on general training, and the worker and the firm share the returns on specific investments. Furthermore, the presence of general training helps to alleviate the firm's incentives to underinvest in specific training and that delayed general training helps to alleviate the worker's incentives to underinvestment in specific training because general and specific training are strategic complements.

I also show that these results are robust to long-term contracts and that several institutional arrangements that help to alleviate the underinvestment problem in specific training may also help to alleviate the underinvestment problem in general training.

Keywords: General and Specific Training, Hold-up Problem, Frictionless Labor Market, Wage Floors
\end{abstract}

JEL-Classification: J41, J24, D21 


\section{Introduction}

In the standard theory of human capital as developed by Becker (1964), there is a sharp distinction between general and specific training. Training is specific to a relationship to the extent that its value is greater within the relationship than outside, whereas is general when is equally valuable inside than outside the relationship. In a competitive labor market, according to the standard Human Capital theory, the analysis of general investments is straightforward. Workers capture the full return on their general training and the firm never pays for general training. ${ }^{1}$ In contrast, specific training combined with contract incompleteness creates quasi-rents that may not be divided ex-post according to the parties ex-ante terms of trade. This renders markets forces insufficient to deter parties not to behave opportunistically; that is, the parties share ex-post their returns to specific investments, and thus, underinvest in specific training takes place. In this paper, I show, consistent with the evidence, that in a frictionless labor market firms usually pay for general training. ${ }^{2}$ Hence, neither credit market restrictions nor labor market imperfections, as argued by Acemoglu and Pischke (1999), are needed to induce firms to provide and pay for general training. Furthermore, as in Becker's Human Capital theory, workers receive the full return on general training and firms and workers share the costs and benefits of specific training.

Our model differs from Becker's model in that I analyze general and specific investments together, yet I assume that general and specific training are neither complements nor substitutes in the production function. So, none of our results are driven by technological considerations. In this framework, I show, first, that general and specific investments are strategic complements. When specific training is analyzed together with general training, the presence of specific training creates quasi-rents that have to be divided ex-post between the worker and the firm according to the outside

\footnotetext{
${ }^{1}$ There is one caveat here, workers must have free access to the credit market.

${ }^{2}$.The evidence on the existence of firm-sponsored general training is vast, see, for instance, Bishop, 1997; Loewenstein and Spletzer, 1998; Pischke, 1997, and Acemoglu and Pischke (1998). The most common examples are the German apprentice system which is common in many countries today, and the temporary help agencies in the U.S., which provide general training to new employees, such as computer skills, and bear the full monetary costs (Autor, 2001).
} 
option principle. That is, the worker gets paid his outside productivity whenever his share of the surplus (output) is lower than his outside productivity, while he shares the total surplus with the firm when his share is larger than his outside productivity. Thus when the surplus sharing outcome arises the firm appropiates, ex-post, a share of the returns to general and specific training. This induces the firm to pay for general training. This plus the fact that the surplus sharing outcome is more likely to arise the larger is the investment in specific training, makes specific and general training strategic complements. Hence, the bilateral monopoly generated by specific training, while creates incentives to underinvest in specific training, it creates incentives to invest in general training.

I also show that the strategic complementarity between specific and general training helps to alleviate the hold-up problem. The reason being that in those states in which the worker gets paid his outside productivity the firm gets the full return on its investment in specific training because the worker's outside productivity depends only on general training. Given that a larger investment in general training increases the worker's outside productivity, more general training makes the firm more likely to get the full return on its investment in specific training.

The strategic complementarity between specific and general training has another benefit that arises only when the firm delays its investment in general training, which is to increase the worker's incentive to invest in specific training. The reason being that a larger investment in specific training results in a larger future wage, because it induces the firm to invest more in general training. In fact I show that when the firm's and the worker's expected payoffs are supermodular, delayed general training is welfare enhancing. The fact that investment in general training is delayed is not at odds with the evidence. For instance, Loewenstein and Spletzer (1997) find that delayed formal training seems to be the norm rather than the exception. ${ }^{3}$

\footnotetext{
${ }^{3}$ An standard example of delayed general training is the MBA graduate education. In many cases the tuition for these programs is partially paid for by the firm at which the students used to work. Furthermore, casual evidence suggests that the longer a worker had been in the company (more specific training accumulated), the more likely is that the firm pays for part of the MBA education. This suggests evidence on the complementarity between specific and general training.
} 
Finally, I argue that these findings are robust to the introduction of long-term contracts and show that some commonly observed institutional arrangements may provide the firm with more incentives to invest and pay for general and specific training. In fact, I show that: (i) a properly chosen minimum wage, contrary to the prediction from the standard Human Capital theory, may increase the equilibrium training levels; and (ii) that an up-or-out rule (Kahn and Huberman, 1988) and the policy of attaching wages to jobs (Prendergast, 1992) may result, not only in more specific training as usually emphasized, but also in more firm-sponsored general training.

Our paper borrows ideas and relates to the literature that attempts to solve the hold-up problem through contractual arrangements. Chung (1991), Aghion et. al. (1994), and Noldeke and Schmidt (1995) analyze contracts, while incomplete, can achieve the efficient outcome. These papers have in common that at the renegotiation stage one party holds the entire bargaining power. ${ }^{4}$ That party, by essentially becoming the residual claimant has the incentive to invest efficiently. Edlin and Reichelstein (1996a, b) assume that parties write a contract that specifies a fixed trade price and a quantity, and after realizing the gains from trade, the parties renegotiate to the ex-post efficient quantity, with the bargaining surplus divided between them according to their relative bargaining power. They show that this renegotiation process by itself leads to underinvestment, but that also each party has an additional incentive to invest in order to improve his disagreement outcome. Hence, under certain conditions, an appropiately chosen initial contract can provide the parties with the right incentives to invest at the socially efficient level. Our analysis, while it borrows from this literature, is different because it concentrates in cooperatives investments, whereas this literature focus on self-specific investments.

Cooperative investments of the type I consider here have received little attention. MacLeod and Malcomson (1993a, b) treat cooperative investments by only one party. They do that through a contract specifying a trade price, and non-trade price and a outside-option price such that the non-investing party outside option is always binding. Since the specific investment does not affect

\footnotetext{
${ }^{4}$ Some of these papers just assume this, while others derive this from a particular bargaining procedure or complicated bonding schemes.
} 
the outside option, the investing party gets the full return of his investment, and therefore invests at the efficient level. Che and Hausch (1999) is the most complete treatment of cooperative investments. Their main finding establishes that when parties cannot commit not to renegotiate and investments are sufficiently cooperative, there exists an intermediate range of bargaining shares for which contracting has no value; that is contracting offers the parties no advantage over spot contracting. ${ }^{5}$ When the investment are purely cooperative, contracting become worthless for the entire range.

There are also other papers showing that firms pay for general training, yet all of these assume that the labor market has frictions. Acemoglu and Pischke (1998, 1999) argue that labor market imperfections may explain why firms pay for general training. They show that when labor markets imperfections distort the structure of wages within the firm away from the competitive benchmark and to the benefit of unskilled workers, it will be profitable for firms to provide workers with general training. The reason being that labor markets imperfections make general skills specific in the sense that trained workers do not get their full marginal product when they switch to another job. Chang and Wang (1996) and Katz and Siderman (1990) make a very similar point in slightly different context. They assume that when investment in general training is not observed by potential employers and is not contractible -so potential employers do not know trained workers's marginal product- trained workers' outside offers do not fully reflect their productivity. They show, as I do, that there is underinvestment in human capital, and that in equilibrium the investment in general training is positively related to the probability that a worker stays with the same employer in the second period. There are no papers as far as I know that address cooperative specific investments coupled with general investments in a competitive market as I do.

The rest of the paper is as follows. In the next section, the model is presented. In section 3 , the efficient training levels are derived. In the next section, section 4, I show that in a frictionless labor market, general and specific training are strategic complements and that firms pay for general

\footnotetext{
${ }^{5}$ They assume as in Edlin and Reichelstein that the bargaining shares of the parties are exogenously specified, yet in their model the parties do not face outside options as is the case in our model.
} 
training. In section 5, I study the consequences of long-term contracts and institutional arrangements over the firm incentives to pay for general training. In particular, I show that a minimum wage law, an up-or-out contract and the policy of attaching the wages to jobs may induce the firm to provide more specific and general training. In the last section concluding remarks are presented.

\section{The Model}

I consider a two-period model between a firm $(f)$ and a worker $(l)$, both of whom are risk neutral. At the beginning of period 1, which is viewed as the early career of the worker, the firm and the worker negotiate a contract for the supply of one unit of labor for each period. At the beginning of period 1 , the worker and the firm undertake non-contractible relationship specific investments, denoted by $s_{l}$ and $s_{f}$, respectively, and after observing these investments the firm decides how much to invest in non-contractible general training, denoted by $g$. At the beginning of period 2, productivity shocks, denoted by $\eta$ and $\varepsilon$, that determines the value of trade at $t=2$ between the incumbent firm and the worker and the market and the worker are realized. After the productivity shocks are realized, the parties may trade at the contract wage, or alternatively, they may either refuse to trade or contract to trade with a third party instead. The parties may also renegotiate the terms of the original contract, but this requires both to agree. In the absence of agreement, either the original contract remains in place or the agents may trade with a third party instead. The renegotiation procedure, which I discuss below, is based on the outside option principle found in Shaked and Sutton (1984). The output (joint surplus) in period 2 is $\mu(\mathbf{s})+v(g)+\eta$, where $\sigma=\left(s_{f}, s_{l}, g\right)$. The output in period 1 is given by the constant $\bar{v}=v(0)$, with $\mu(0)=0$ and $v(0) \geq 0,{ }^{6}$ which is the productivity of the worker when there is no investment in specific and general training. For trade with third parties, let $v(g)+\varepsilon$ and $\pi \geq 0$ denote the worker's and the firm's second period payoffs, respectively.

Notice that general and specific training are neither complements nor substitutes in the pro-

\footnotetext{
${ }^{6}$ Bold denotes vectors.
} 
duction function and that general training has the same marginal product inside the firm as in the market; that is, $g$ is complete general in the sense of Becker's (1964). This is to ensure that our results do not depend on either the complementarity or substitutability of general and specific training.

- Assumption 1: (i) For all $\mathbf{s} \in \Omega, \mu(\mathbf{s})$ is bounded above, $C^{2}$ and strictly concave in $\mathbf{s}$; (ii) $\lim _{s_{i} \rightarrow 0} \mu_{s_{i}}(\mathbf{s}) \rightarrow \infty$ and $\lim _{s_{i} \rightarrow \infty} \mu_{s_{i}}(\mathbf{s}) \rightarrow 0$ for $i=f, l$; (iii) For all $g \geq 0, v(g)$ is bounded, $C^{2}$, and strictly concave; and (iv) $\lim _{g \rightarrow 0} v_{g}(g) \rightarrow \infty$ and $\lim _{g \rightarrow \infty} v(g) \rightarrow 0$.

- Assumption 2: (i) The productivity shock $\eta$ is distributed $f[\underline{\eta}, \bar{\eta}]$ and is independent of $\sigma$; and (ii) the productivity shock $\varepsilon$ is distributed $h[\underline{\varepsilon}, \bar{\varepsilon}]$ and is also independent of $\sigma$.

Because the firm and the worker are risk neutral and investments are measured by their costs, the potential surplus of continuing the relationship after shocks are realized is well-defined and given by

$$
S(\sigma, \eta, \varepsilon)=\max \{\mu(\mathbf{s})+v(g)+\eta, v(g)+\varepsilon+\pi\} .
$$

For the sake of simplicity, I assume from now on that $\pi=0 .^{7}$

\section{A Benchmark: The First Best Outcome}

In this section I determine the efficient investment levels. This requires that for every training level $\sigma$ and states $\eta$ and $\varepsilon$, trade be at an efficient level; that is, separations take place if and only if $\mu(\mathbf{s})+v(g)+\eta<v(g)+\varepsilon$. Given efficient trading, the efficient investment further requires that $\sigma$ maximizes the total expected gains from the employment relationship independently if a separation occurs. That is, $\sigma$ maximizes $S(\sigma)$, which is given by

$$
E_{\varepsilon}\left\{\int_{\varepsilon-\mu(s)}^{\bar{\eta}}(\mu+v+\eta) d F(\eta)+\int_{\underline{\eta}}^{\varepsilon-\mu(s)}(v+\varepsilon) d F(\eta)\right\}-s_{f}-s_{l}-g .
$$

\footnotetext{
${ }^{7}$ This assumption is consistent with a competitive labor market since, when there is no specific training the firm has to pay a worker his total productivity.
} 
I assume that $S(\sigma)$ is strictly concave. Given assumptions 1 and 2 , this results in a unique maximizer $\sigma^{*}>\mathbf{0}$. Using the envelope theorem, the efficient investment level, denoted by $\sigma^{*}$, is determined by the following first-order conditions

$$
\begin{gathered}
\mu_{s_{f}}\left(\mathbf{s}^{*}\right)\left[1-E_{\varepsilon} F\left(\mathbf{s}^{*}, \varepsilon\right)\right]-1=0, \\
\mu_{s_{l}}\left(\mathbf{s}^{*}\right)\left[1-E_{\varepsilon} F\left(\mathbf{s}^{*}, \varepsilon\right)\right]-1=0, \\
v_{g}\left(g^{*}\right)-1=0,
\end{gathered}
$$

where $E_{\varepsilon} F\left(\mathbf{s}^{*}, \varepsilon\right)$ is the probability that a separation occurs.

Notice that the fact that $g$ is completely general in the sense of Becker (1962) results in that the probability of a separation is independent of the level of general training. That is, the firstorder condition for general training reflects that the probability of separation is independent of the level of general training. Notice, also, that the first-order conditions for the relationship-specific investments reflect the fact that changes in specific investments affect the probability of a match through states at which the gains from matching are exactly outweigh by the gains from separation and the specific investment efficient levels are independent of the investment in general training.

\section{General Training without Frictions}

\subsection{Main Results}

In this section it is assumed that no long-term contracts are written and that the labor market is perfectly competitive; that is, there is no frictions of any kind. This is the same environment in which Becker (1962) derived his famous result that there is no firm sponsored general training. In this case the wage is determined by ex-post negotiation, which takes place right after uncertainty is realized. Because there is complete information, this bidding process ensures that trade is efficient. 
To see that, consider, first, the case in which $\mu(\mathbf{s})+v(g)+\eta<v(g)+\varepsilon$. Then what is generated by continuing the relationship is less than what can be generated if firm and the worker break apart, thus there is no way to divide the surplus so that both, the firm and the worker prefer, at least weakly, to continue the relationship. Consider next the case in which $\mu(\mathbf{s})+v(g)+\eta \geq v(g)+\varepsilon$. In this case, continuing the relationship generates more than separating out, hence, given that there is full information it is possible to redistribute the gains from the relationship in a way that both, the firm and the worker prefer to continue the relationship. Hence, it follows from this and the outside option principle (see, for instance, Shaked and Sutton, 1984) that the payoffs arising from renegotiation are given by $((1-\alpha)[\mu(\mathbf{s})+v(g)+\eta], \alpha[\mu(\mathbf{s})+v(g)+\eta])$ if $\eta \geq \frac{(1-\alpha) v(g)+\varepsilon}{\alpha}-\mu(\mathbf{s})$ and $(\mu(\mathbf{s})+\eta-\varepsilon, v(g)+\varepsilon)$ otherwise, where $\alpha$ is the worker's bargaining power and the first entry corresponds to the firm's payoff and the second to the worker's payoff. ${ }^{8}$ Notice that a worker receives at least his outside option and that the firm sometimes share part of the return to general training with the worker.

Given this the firm's period-2 expected payoff, denoted by $U_{f}^{s}(\sigma)$, is ${ }^{9}$

$$
E_{\varepsilon}\left\{\int_{\frac{(1-\alpha) v+\varepsilon}{\alpha}-\mu}^{\bar{\eta}}(1-\alpha)(\mu+v+\eta) d F(\eta)+\int_{\varepsilon-\mu}^{\frac{(1-\alpha) v+\varepsilon}{\alpha}-\mu}(\mu+\eta-\varepsilon) d F(\eta)\right\},
$$

while the worker's period-2 expected payoff, denoted by $U_{l}^{s}(\sigma)$, is

$$
E_{\varepsilon}\left\{\int_{\frac{(1-\alpha) v+\varepsilon}{\alpha}-\mu}^{\bar{\eta}} \alpha(\phi+\eta) d F(\eta)+\int_{\underline{\eta}}^{\frac{(1-\alpha) v+\varepsilon}{\alpha}-\mu}(v+\varepsilon) d F(\eta)\right\} .
$$

\footnotetext{
${ }^{8}$ We have assumed that the outside options do not work as threat points based on the arguments in Binmore et. al. (1984). The outside option can work as threat point only when either party can take his outside option for one bargaining round and come back to keep bargaining after that period. Furthermore, the parties have to be paid exactly their outside options during that period in order to have outside options to work as threat points. In the case in which the payment that the parties receive during the period of suspended bargaining are different from the outside options, our results applied under a Nash bargaining solution. Hence, I assume for the sake of simplicity that the default payoffs the parties receive while they continue bargaining are both equal to 0 .

${ }^{9}$ We omit the arguments to decrease the notational burden.
} 
Assuming that the second-order-conditions are satisfied, the optimal investment under spotcontracting, denoted by $\sigma^{s}=\left(s_{f}^{s}, s_{l}^{s}, g^{s}\right)$, is determined by the following first-order conditions

$$
\begin{gathered}
\mu_{s_{f}}\left[1-E_{\varepsilon} F(\varepsilon-\mu)\right]-\alpha \mu_{s_{f}}\left[1-E_{\varepsilon} F\left(\frac{(1-\alpha) v+\varepsilon}{\alpha}-\mu\right)\right]-1=0 \\
v_{g}-v_{g}\left[\alpha+(1-\alpha) E_{\varepsilon} F\left(\frac{(1-\alpha) v+\varepsilon}{\alpha}-\mu\right)\right]-1=0 \\
\alpha \mu_{s_{l}}\left[1-E_{\varepsilon} F\left(\frac{(1-\alpha) v+\varepsilon}{\alpha}-\mu\right)\right]+ \\
v_{g} \frac{\partial g}{\partial s_{l}}\left[\alpha+(1-\alpha) E_{\varepsilon} F\left(\frac{(1-\alpha) v+\varepsilon}{\alpha}-\mu\right)\right]-1=0 .
\end{gathered}
$$

Notice that marginal return on $s_{f}$ under spot contracting is lower than the marginal return in the efficient case by the second term in the first-order condition for $s_{f}$. This term arises because there is a positive probability, given by $1-E_{\varepsilon} F\left(\frac{(1-\alpha) v+\varepsilon}{\alpha}-\mu\right)$, that the worker's outside option is non-binding. In this case the firm has to share the marginal return of his investment with the worker according to its bargaining power; i.e., $1-\alpha$. The first-order condition for $g$ reflects the fact that the firm captures $1-\alpha$ of the marginal return on general training when the worker's outside option is non-binding, while when is binding, the firm pays the worker his outside option. This last case corresponds to Becker's Human capital model. Notice also that the first-order conditions for $s_{f}$ and $g$ are not affected by the fact that general training is chosen after the specific investments are made and observed by both parties. Whereas the first-order condition for $s_{l}$ is affected by the assumption that general training is delayed.

The first term in 4, which is independent of whether general training is delayed or not, reflects the fact that the worker captures only a fraction $\alpha$ of the marginal return on $s_{l}$ when the worker's outside option is non-binding and captures nothing when its binding because his outside option is independent of the investment in specific training. The second term arises because of delayed general training; that is, if general training were chosen simultaneously with $\mathbf{s}$ the second term will be zero. Notice that the effect of this second term on the worker's incentives to invest in 
specific training depends exclusively on the sign of $\frac{\partial g}{\partial s_{l}}$. Hence, if general and specific training are strategic complements (substitutes), then delayed general training provides the worker with more (less) incentives to invest in specific training than simultaneously chosen general training. Then it is crucial to understand the benefits of delayed general training to find out under what conditions general and specific training are strategic complements.

Fortunately, it readily follows from the firm's first-order condition for general training that general and specific training are always strategic complements even though they are neither complements nor substitutes in the production function. The reason being that under spot contracting the worker and the firm will share the surplus with positive probability and the probability that the surplus sharing outcome arises is increasing in $s_{i}$ for $i=f, l$. This leads to the following very crucial result.

Proposition 1 Suppose a competitive labor market with no frictions. Then, general and specific training are strategic complements.

proof: $\frac{\partial U_{f}^{s}(\sigma)}{\partial g \partial s_{i}}=v_{g} \mu_{s_{i}} E_{\varepsilon} f\left(\frac{(1-\alpha) v+\varepsilon}{\alpha}-\mu\right)>0$ for all $\mathbf{s}$ and $g$.

This results implies that the presence of general training has two effects on the incentives to undertake specific investments. One that increases the firm's incentives to invest in specific training and that is independent of whether general training is delayed or not, and another one that increases the worker's incentives to invest, which is the result of delayed general training. To better understand the first effect, suppose, for simplicity, that the firm cannot or does not invest in general training and that $\mu(\mathbf{s})+v(0)+\underline{\eta} \geq v(0)+\bar{\varepsilon}$. In this case surplus sharing always occur and the firm and the worker share the benefits of their specific investments, and thus, the firm has an incentive to underinvest. Suppose next that the firm can commit to invest in general training, then there is a set of states under which $\mu(\mathbf{s})+v(g)+\eta \geq v(g)+\varepsilon$ and $\alpha(\mu(\mathbf{s})+v(g)+\eta)<v(g)+\varepsilon$. This implies that there is a set of states under which the firm's payoff is given by $\mu(\mathbf{s})+\eta-\varepsilon$. Hence, the firm, in those states, will get full marginal return on his investment providing the firm with incentives to invest at the efficient level. 
That delayed general training induces the worker to invest more in specific training follows from that a larger investment in specific training by the worker, results in a larger probability that the surplus sharing outcome arises. This implies that the firm has more incentives to invest in general training and therefore, the worker can ensure a larger second period wage. While these two effects together may induce the firm and the worker to invest more in specific training, they are not powerful enough to overcome the parties incentives to underinvest relative to the efficient levels. Hence, the parties never undertake the efficient investment levels. The following proposition then follows.

Proposition 2 Suppose a competitive labor market with no frictions. Then, (i) if the specific investments are strategic complements, $s_{f}^{s}<s_{f}^{*}$, $s_{l}<s_{l}^{*}$ and $0<g^{s}<g^{*}$; while if they are strategic substitutes, $s_{f}^{s}<s_{f}^{*}, s_{l} \gtreqless s_{l}^{*}$ and $0<g^{s}<g^{*}$; and (ii) separations are always efficient.

So far, I have shown that (i) the firm invests in general training, but at sub-optimal level; and (ii) while the worker may overinvest in specific training, the firm always underinvest in specific training. Thus the market never provides with incentives powerful enough to induce both, the firm and the worker to undertake the efficient investments levels.

Notice that I have shown, so far, that the firm provides the worker with general training, yet this does not mean that there is firm-sponsored general training because the firm may recoup the investment costs, as in Becker, in the first period by mean of a lower first-period wage. Hence, it is crucial to study whether the firm will lower the first-period wage enough to recoup its investment in general training.

Under spot contracting firms compete for workers in a Bertrand-like fashion in the first period, with the known result that in equilibrium firms have zero expected profits. Hence, first-period wage is given by

$$
w_{1}=\bar{v}+U_{f}\left(\sigma^{s}\right)-g^{s}-s_{f}^{s} \geq \bar{v} .
$$

The last inequality follows from the fact that the firm can always ensure a payoff of at least 
zero by investing zero and hiring an untrained worker or closing down. Hence, the following results obtains.

Proposition 3 Suppose a competitive labor market with no frictions. Then, (i) there is firmsponsored general training; and (ii) the firm and the worker share the costs and benefits of specific training.

The first result in this proposition is crucial since it is in stark contrast to Becker's Human Capital Theory and Acemoglu's and Pishcke's $(1998,1999)$ results that firm-sponsored general training arises if and only if there is market frictions. Our results shows that in a competitive labor market with no frictions and where general and specific training are neither complements nor substitutes, firms pay for general training. Hence, as the evidence shows (see, for instance, Bishop (1996), Lowestein and Spletzer (1998), Acemoglu and Pischke (1998)) firm-sponsored general training is the norm rather than the exception.

What makes our result different from Becker's and Acemoglu and Pischke's results is that general and specific training are strategic complements even though they are neither complements nor substitutes in the production function.

\subsection{Some Remarks}

I have, so far, assumed that general training is delayed and shown that delayed general training improves worker incentives to invest in specific training. This may seem an ad-hoc assumption, but it can be shown that there are conditions under which delayed general training is welfare enhancing. Furthermore, the only paper that I are aware off that study the timing of investment in general training, Loewenstein and Spletzer (1997), find that delayed formal training seems to be the norm rather than the exception.

Before doing so let define $S\left(\sigma^{s}\right)$ as $U_{f}^{s}(\sigma)+U_{l}^{s}(\sigma)-g-s_{f}-s_{l}$. Then the following result obtains. 
Proposition 4 Suppose that $U_{f}^{s}(\sigma)-g-s_{f}$ is supermodular. Then, under delayed general training, $S\left(\sigma^{s}\right)$ is larger than when general and specific training are chosen simultaneously.

Proof: It readily follows from theorem 7 in Milgrom and Roberts (1990).

The intuition can be easily grasp from figures 1, 2 and 3. From figure 3, I can see that when the expected payoff functions are both submodular, the reaction functions are downward sloping, and thus welfare may decrease because the firm's investment in specific training may be lower than when training is chosen simultaneously. While if the firm's expected payoff function is supermodular (figures 1 and 2), then the firm's reaction function is upward sloping. Because the worker's reaction function is larger in the presence of delayed general training and general and specific training are strategic complements, then the equilibrium investment level are larger in the presence of delayed general training. Hence, welfare is larger under delayed general training.

I have also assumed that only the firm invests in general training. Hence, it is natural to ask how our results change if I allow the worker to invest in general training. If I assumed that the worker decision is delayed too, then the worker's investment in general training is given by the following first-order condition

$$
v_{g}\left[\alpha+(1-\alpha) E_{\varepsilon} F\left(\frac{(1-\alpha) v+\varepsilon}{\alpha}-\mu\right)\right]-1=0
$$

It readily follows from this that for all $\alpha<1, g^{s}<g^{*}$. Furthermore, because of Bertrand-like competition in period 1 , the first-period wage is given by

$$
w_{1}=\bar{v}+U_{f}\left(\sigma^{s}\right)-g^{s}-s_{f}^{s}-g^{s} \geq \bar{v}-g^{s} .
$$

Hence, the following result obtains.

Proposition 5 If only the worker invests in general training, then there is firm-sponsored general training and $g^{s} \leqq g^{*}$.

Finally our result seems to rest heavily on the presence of specific investments. However, what is really needed for it to hold is that there is a positive probability that the surplus sharing outcome 
arises. Suppose, then, that $\mathbf{s}^{s}=\mathbf{0}$, if the probability that $\eta \geq \frac{(1-\alpha) v(g)+\varepsilon}{\alpha}-\mu(\mathbf{0})$ is positive, then there is firm-sponsored general training.

Proposition 6 Suppose that $s_{f}^{s}=s_{l}^{s}=0$, if $\eta \geq \frac{(1-\alpha) v(g)+\varepsilon}{\alpha}$ for some $\eta$ and $\varepsilon$, then $g^{s}>0$.

This corollary shows that in order to have firm-sponsored general training I only need the existence of match specific shocks coupled with a positive worker's bargaining power. Yet, the conditions to have firm sponsored general training in the absence of specific training are rather ad-hoc because they depend on the support of $\eta$ and $\varepsilon$.

\section{Long-Term Contracts}

Up to this point I have restricted our attention to an incomplete contracting setting in which no long-term contracts are allowed. In this section, I consider the possibility that the firm and the worker may sign a long term contract to study two issues: (i) is the firm-sponsored general training result robust to long-term contracts as the one observed in real life?; and if so (ii) Do these long-term contracts increase or increase investment incentives?

For the sake of brevity and simplicity, I focus hereafter on the simpler case in which the outside productivity is not affected by an idiosyncratic productivity shock; that is, the worker's value in the market is just $v(g)$.

\subsection{A Fixed Wage Long-Term Contract}

In this section, I consider the role of a renegotiable long-term contract that specifies fixed wages $\left(w_{1}, w_{2}\right)$. As with spot contracting, because there is perfect information at the time of renegotiation, bargaining is efficient and the employment relationship continues only if it is beneficial for the parties involved. If $\mu(\mathbf{s})+v(g)+\eta<v(g)$, the parties cannot do better than separate and take-up their outside opportunities with the corresponding payoffs of 0 and $v(g)$. If $\mu(\mathbf{s})+v(g)+\eta-w_{2}>0$ and $w_{2} \geq v(g)$, then the firm and the worker prefer trading at the original contract wage $w_{2}$ to take the outside option or simply refusing to trade. Thus, if one party refuses to renegotiate, then 
the other always prefers to trade rather than to quit or hold-up exchange. Since trade is efficient, renegotiation can at best only redistribute the gains from relationship, consequently it will always be in the interests of one party to refuse to renegotiate. If $\mu(\mathbf{s})+v(g)+\eta>v(g)$, but one of the parties prefer either no to trade or the outside option to the current contract terms; that is, either $\mu(\mathbf{s})+v(g)+\eta-w_{2}<0$ or $v(g)>w_{2}$, it follows from the outside option principle that the payoffs arising from renegotiation are given $((1-\alpha)[\mu(\mathbf{s})+v(g)+\eta], \alpha[\mu(\mathbf{s})+v(g)+\eta])$ if $\eta \geq \frac{(1-\alpha) v(g)+\varepsilon}{\alpha}-\mu(\mathbf{s})$ and $(\mu(\mathbf{s})+\eta-\varepsilon, v(g)+\varepsilon)$, otherwise.

Notice that the key difference between a long-term contract and spot contracting is given by the case in which neither outside option is binding. In this case, under spot contracting the firm and the worker share the total surplus, while under a long-term contract the firm's payoff become $\mu(\mathbf{s})+v(g)+\eta-w_{2}$. That is, in those states in which neither outside option binds, the firm gets the full marginal return on its investments and the workers' investment. Thus, apparently the firm's incentives to invest in general and specific investments increase and the worker's incentive decrease.

Notice first that a long-term contract has a potential value only if $\mu(\mathbf{s})+v(g)+\bar{\eta}>w_{2} \geq v(g)$, otherwise renegotiation always takes place and therefore, contracting has no value. Hence, I will assume that this restriction is satisfied.

Given this, the firm's period-2 expected payoff, denoted by $U_{f}^{L}\left(\sigma, w_{2}\right)$, is

$$
\begin{aligned}
& \int_{w_{2}-\mu-v}^{\bar{\eta}}\left(\mu+v+\eta-w_{2}\right) d F(\eta)+ \\
& I(\alpha)\left[\int_{\frac{(1-\alpha) v}{\alpha}-\mu}^{w_{2}-\mu-v}(1-\alpha)(\mu+v+\eta) d F(\eta)+\int_{-\mu}^{\frac{(1-\alpha) v}{\alpha}-\mu}(\mu+\eta) d F(\eta)\right]+ \\
& (1-I(\alpha)) \int_{-\mu}^{w_{2}-\mu-v}(\mu+\eta) d F(\eta),
\end{aligned}
$$

where $I(\alpha)$ is an indicator function that takes the value 1 when $\alpha \geq \frac{v(g)}{w_{2}}$ and 0 , otherwise. 
The worker's period-2 expected payoff, denoted by $U_{w}^{L}\left(\sigma, w_{2}\right)$, is

$$
\begin{aligned}
& \int_{w_{2}-\mu-v}^{\bar{\eta}} w_{2} d F(\eta)+ \\
& I(\alpha)\left[\int_{\frac{(1-\alpha) v}{\alpha}-\mu}^{w_{2}-\mu-v} \alpha(\mu+v+\eta) d F(\eta)+\int_{\underline{\eta}}^{\frac{(1-\alpha) v}{\alpha}-\mu} v d F(\eta)\right]+ \\
& (1-I(\alpha)) \int_{\underline{\eta}}^{w_{2}-\mu-v} v d F(\eta) .
\end{aligned}
$$

Notice that the firm's and worker's payoff have three components. The first one corresponds to the case in which the firm's outside option never binds, the second one to the case in which is binding, but is optimal to continue the relationship and the third one, to the case in which separation is optimal. The second one could be composed of either one or two terms depending on the worker's bargaining power. The first of these two terms takes place when the worker's bargaining power is sufficiently large; i.e., $\alpha \geq \frac{v\left(g^{L}\right)}{w_{2}}$, so that when the firm outside option binds, there is a positive probability that the surplus sharing outcome arises. Whereas the second occurs when $\alpha$ is small enough so that the surplus sharing outcome yields the worker less than his outside option.

The first-order conditions can, after some simple algebra, be written as

$$
\begin{gathered}
\frac{\partial U_{f}^{s}}{\partial s_{f}}+\mu_{s_{f}} M\left(w_{2}, \alpha, \sigma\right)-1=0, \\
\frac{\partial U_{f}^{s}}{\partial g}+v_{g}\left(M\left(w_{2}, \alpha, \sigma\right)+N\left(w_{2}, \alpha, \sigma\right)\right)-1=0, \\
\frac{\partial U_{w}^{s}}{\partial s_{l}}-\mu_{s_{l}} M\left(w_{2}, \alpha\right)-v_{g} \frac{\partial g}{\partial s_{l}}\left(M\left(w_{2}, \alpha, \sigma\right)+N\left(w_{2}, \alpha, \sigma\right)\right)-1=0,
\end{gathered}
$$

where

$$
\begin{aligned}
M\left(w_{2}, \alpha, \sigma\right) \equiv & (1-I(\alpha)) \alpha\left[1-F\left(\frac{(1-\alpha) v}{\alpha}-\mu\right)\right]+ \\
& I(\alpha) \alpha\left[1-F\left(w_{2}-\mu-v\right)\right]- \\
& f\left(w_{2}-\mu-v\right)\left[I(\alpha)(1-\alpha) w_{2}+(1-I(\alpha))\left(w_{2}-v\right)\right],
\end{aligned}
$$

and 


$$
N\left(w_{2}, \alpha, \sigma\right) \equiv(1-I(\alpha))\left[F\left(\frac{(1-\alpha) v}{\alpha}-\mu\right)-F\left(w_{2}-\mu-v\right)\right]+I(\alpha) 0
$$

The first question I attempt to answer is whether firm-sponsored general training is affected positively or negatively by a long-term contract. If I focus our attention on the first-order condition for general training, I see clearly that if $M\left(w_{2}, \alpha, \sigma\right)+N\left(w_{2}, \alpha, \sigma\right) \geq 0$ when evaluated at $\sigma=\sigma^{s}$, then the amount of training under a long-term contract, denoted by $g^{L} \geq g^{s}$. While if $M\left(w_{2}, \alpha, \sigma\right)+$ $N\left(w_{2}, \alpha, \sigma\right)<0$ when evaluated at $\sigma=\sigma^{s}, g^{L}<g^{s}$.

Notice that, as under spot contracting, general and specific training are strategic complements. ${ }^{10}$ Hence, under a contract in which $M\left(w_{2}, \alpha, \sigma\right)>0$ and $M\left(w_{2}, \alpha, \sigma\right)+N\left(w_{2}, \alpha, \sigma\right) \geq 0$, the firm's incentives to invest in general and specific training improve upon the market, while the worker's incentive worsens. While the opposite occurs when $M\left(w_{2}, \alpha, \sigma\right)<0$ and $M\left(w_{2}, \alpha, \sigma\right)+N\left(w_{2}, \alpha, \sigma\right)<$ $0 .{ }^{11}$ Notice also that $N\left(w_{2}, \alpha, \sigma\right)$ is always positive, so $M\left(w_{2}, \alpha, \sigma\right)+N\left(w_{2}, \alpha, \sigma\right)<0$ if and only if $M\left(w_{2}, \alpha, \sigma\right)<0$. This implies that there is no equilibrium under which firm's incentives to invest in general and specific training increase and the worker's incentives to invest in specific training also increase.

In the next lemma I find conditions under which a long term contract improves the firm's incentive to invest in general training.

\footnotetext{
${ }^{10}$ This result does not hold always when the outside productivity is random, but it holds in that case under fairly general conditions.

${ }^{11}$ Che and Hausch (1999) show that if the seller's (firm) and buyer's (worker) payoffs are supermodular, then there is a non-empty set of $\alpha$ 's under which contracting has no value. That is, spot contracting provides as much welfare as any other general contract. This results does not hold in our setting even if we assume that $\frac{\partial g}{\partial s_{w}}=0$. The reason being that if $M(w, \alpha)>0$, the firm has better incentives under a long-term contract than under spot contracting, while the worker has less incentives. Whereas, if $M(w, \alpha)<0$, the opposite occurs. Hence, it is never the case that both, the firm and the worker have less incentives to invest in specfic training under a long-term contract. That is, the set $[\underline{\alpha}, \bar{\alpha}]$ defined by Che and Haush, when adopted to our setting, is empty. Furthermore, if $\frac{\partial g}{\partial s_{w}} \neq 0$, then our setting differs from theirs in that we have a sequential setting that affects the worker's incentives to invest.
} 
Lemma 7 (i) Suppose that $\alpha \geq \frac{v\left(g^{L}\right)}{w_{2}}$. Then, if $1-F\left(w_{2}-\mu-v\right)-\frac{w_{2}\left(w_{2}-v\right)}{v} f\left(w_{2}-\mu-v\right)<0$, there exists an $\alpha$, denoted by $\tilde{\alpha}$, such $M\left(w_{2}, \alpha, \sigma\right)+N\left(w_{2}, \alpha, \sigma\right) \geq 0$ for all $\alpha \in\left[\frac{v\left(g^{L}\right)}{w_{2}}, \tilde{\alpha}\right)$; and (ii) suppose that $\alpha<\frac{v\left(g^{L}\right)}{w_{2}}$, then $M\left(w_{2}, \alpha, \sigma\right)+N\left(w_{2}, \alpha, \sigma\right) \geq 0$ for all $\alpha \in[0, \hat{\alpha})$.

The intuition is as follows when $\alpha$ is small an increase in $g$ increases the probability that the outside option is binding more than increases the probability that the firm's outside option is nonbinding. Because when the outside option is binding the firm captures no share of the return on general training, the incentives to invest in general training decrease. Hence, long-term contracts may, under certain conditions, decrease the firm's incentives to invest in general training provided by the market alone.

Given these definitions the following can be shown. ${ }^{12}$

Proposition 8 (i) There is no long-term contract that implements efficient investment levels in training; (ii) there is no long-term contract under which both, the firm and the worker have better incentives to invest in training over spot-contracting; (iii) if $\mathbf{s}^{L} \geq \mathbf{s}^{s}$ and $M\left(w_{2}, \alpha, \sigma\right)+N\left(w_{2}, \alpha, \sigma\right)>$ 0 , then $g^{L}>g^{s}$, while if $\mathbf{s}^{L} \leqq \mathbf{s}^{s}$ and $M\left(w_{2}, \alpha, \sigma\right)+N\left(w_{2}, \alpha, \sigma\right) \leqq 0$, then $g^{L} \leqq g^{s}$.

This proposition makes clear that there is no contract that can implement the efficient investment level in specific and general training and that in some cases a long-term contract may induce the firm to invest less in general training and sometimes to invest more in general training. Furthermore, it is never the case that long-term contracts can provide the firm and the worker at the same time with better incentives to invest in specific training than a frictionless market does. This is, basically, due to cooperative nature of specific training.

To see that this is true, I will assume in the next proposition that the worker's efficient investment is either zero or the worker can commit to invest $s_{f}^{*}$ or the worker invests in specific self investments and show that under certain conditions, there is a long-term contract that induces the firm to invest at the efficient level in specific and general training.

\footnotetext{
${ }^{12}$ Similar results obtains if breach penalties are allowed.
} 
Proposition 9 Suppose that $U_{f}^{L}\left(\mathbf{s}^{*}, g^{L}, w_{2}\right) \geq 0, \phi\left(\mathbf{s}^{*}, g^{L}\right)+\underline{\eta}>v\left(g^{L}\right)$ and either $s_{l}=0$ or the worker can commit to invest $s_{l}=s_{l}^{*}$ or $s_{l}$ does not affect the joint surplus. Then (i) there exists a long-term contract with $\phi\left(\mathbf{s}^{*}, g^{L}\right)+\underline{\eta}>w_{2} \geq v\left(g^{L}\right)$, such that the firm's optimal investment is $s_{f}^{L}=s_{f}^{*}$ and $g^{L}<g^{*}$ if $\alpha>\frac{v\left(g^{*}\right)}{w_{2}}$ and $g^{L}=g^{*}$ if $\alpha \leqq \frac{v\left(g^{*}\right)}{w_{2}}$.

The intuition for this results follows from the fact that under the assumptions made, there is no renegotiation in equilibrium and thus, the firm is the full residual claimant of the return to specific and general training.

So far I have shown that under a long-term contract $g^{L} \lesseqgtr g^{s}$, but I have not shown yet that there is firm-sponsored general training. Competition in the first period ensures that

$$
w_{1}=\bar{v}+U_{f}^{L}\left(\sigma^{L}\right)-g^{L}-s_{f}^{L} \geq \bar{v} .
$$

This inequality holds because the firm can always ensure itself a payoff equal to zero by refusing to trade and investing zero or by hiring an untrained worker. This results in that $w_{1} \geq \bar{v}$. Hence, the worker's first period wage is larger than the wage that he would have obtained were he bears the full cost of his specific and general training. This leads us to the following result.

Proposition 10 Under a long-term contract there is firm-sponsored general training whenever $g^{L}>0$.

In the next section, I study whether different contractual provisions may provide better incentive to undertake general and specific investments. If the complementarity between general and specific training holds under other contractual provisions that induce more investment in specific training, I can show that the same provisions may result in more firm-sponsored general training. This is the issue I study in the next section.

\subsection{Long-Term Contracts With Wage Floors}

The impossibility of increasing the parties incentives to invest under long-term contracts is due, partially, to the cooperative nature of investments and that renegotiation always takes place. That 
is, there are always states under which either the firm or the worker or both have to share the returns to their investment with each other. This lead us to study the possible safeguards that commonly observed contractual provisions can provide to alleviate the incentives to under-invest. In our view one the main contributions of some contractual provisions is the possibility of commitment to certain actions by either party. In particular, I consider three commonly observed institutional arrangements that have as a common factor that they preclude the firm from renegotiating the wage downwards, but not necessarily upwards. These are: (i) minimum wages, (ii) up-or-out rules as the one used in academic markets and law firms; and (iii) the policy of attaching wages to jobs as used for instance in public sector jobs.

\subsubsection{A Minimum Wage Contractual Provision}

In this section I will consider the imposition of a minimum wage that is binding. That is a minimum wage, denoted by $\underline{w}$, that is above the worker's outside option; i.e., $\underline{w}>v(g) .{ }^{13}$

It is well known since Rosen (1972) that the imposition of a minimum wage in Becker's human capital model cannot lead to an increase in general training. The reason being straightforward: because workers pay for training through lower wages, a minimum wage may prevent the firm from lowering the wage enough during the first period. This is, for instance, the rationale for introducing a "training subminima" in many recent U.S. minimum wage laws. In this section I show that a minimum wage can have the opposite effect; that is, it can improve firm's incentives to invest in general and specific training.

Under a minimum wage $\underline{w}$ the firm's second period expected payoff is

$$
U_{f}^{m}(\sigma, \underline{w})=\int_{\underline{w}-\mu-\nu}^{\bar{\eta}}(\mu+\nu+\eta-\underline{w}) d F(\eta),
$$

while the worker's expected payoff is

$$
U_{w}^{m}(\sigma, \underline{w})=\int_{\underline{w}-\mu-\nu}^{\bar{\eta}} \underline{w} d F(\eta) .
$$

\footnotetext{
${ }^{13}$ Notice that if the minimum wage is below $v(g)$, then the market behaves as an spot contracting market and the minimum imposes no constraint in the wage setting process.
} 
Notice that when the firm needs to lower the wage because it faces a low productivity shock, the firm cannot do so because the minimum wage law impedes to downward renegotiate the wage as efficiency requires. Hence, the firm has to fire the worker, creating unemployment. ${ }^{14}$

The first-order conditions are then given by

$$
\begin{gathered}
\frac{\partial U_{f}^{s}(\sigma)}{\partial s_{f}^{m}}+ \\
\mu_{s_{f}}\left\{\alpha\left[1-F\left(\frac{(1-\alpha) v}{\alpha}-\mu\right)\right]+F(-\mu)-F(\underline{w}-\mu-\nu)\right\}-1=0, \\
v_{g}\left\{\alpha \left[1-F\left(\frac{\partial U_{f}^{s}(\sigma)}{\partial g^{m}}+\right.\right.\right. \\
\left.\left.\left.\left.\left.\frac{(1-\alpha) v}{\alpha}-\mu\right)\right]+F\right) v-\mu\right)-F(\underline{w}-\mu-\nu)\right\}-1=0, \\
\frac{\partial U_{w}^{s}(\sigma)}{\partial s_{l}}+\mu_{s_{l}}\left\{\underline{w} f(\underline{w}-\mu-\nu)-\alpha\left[1-F\left(\frac{(1-\alpha) v}{\alpha}-\mu\right)\right]\right\}+ \\
v_{g} \frac{\partial g^{m}}{\partial s_{l}}\left\{\underline{w} f(\underline{w}-\mu-\nu)-\left[\alpha+(1-\alpha) F\left(\frac{(1-\alpha) v}{\alpha}-\mu\right)\right]\right\}-1=0 .
\end{gathered}
$$

It readily follows from the firm's first-order conditions that the firm's incentive to invest in specific and general training are larger under a minimum wage than under the spot market when $M(\alpha, \underline{w}) \equiv \alpha\left[1-F\left(\frac{(1-\alpha) v}{\alpha}-\mu\right)\right]+F(-\mu)-F(\underline{w}-\mu-\nu) \geq 0$. This term is the result of the combination of two effects; one positive that increases the firm's return on specific training and one negative that lowers it. The positive effect arises because there is a positive probability that the minimum wage is not binding for the firm, and therefore, a positive probability that the firm is the full residual claimant. The negative effect arises because there are states under which it is optimal to renegotiate the wage downwards, but the minimum wage law does not allows it, and therefore, a separation occurs more often than it should be. Finally, notice that general and specific training are strategic complements..$^{15}$

Lemma 11 There exists a wage $\tilde{w}$ such that $M(\alpha, \underline{w}, \sigma) \geq 0$ for all $\underline{w} \leqq \tilde{w}$.

\footnotetext{
${ }^{14}$ If firms are heterogeneous, a minimum wage also generates unemployment because there are some firms that without a minimum wage would be willing to hire workers in period 1, while under a minimum wage law they are not willing to do so.

${ }^{15}$ This readily follows from differentiating the firm's first-order condition for general training.
} 
This results readily follows from the continuity of $M(\alpha, \underline{w}, \sigma)$ and the fact that $M\left(\alpha, \underline{w}, \sigma \mid \underline{w}=v\left(g^{m}\right)\right)>$ 0. Hence, the following result obtains.

Proposition 12 Suppose that $U_{w}^{m}(\sigma, \underline{w})$ and $U_{f}^{m}(\sigma, \underline{w})$ are supermodular. Then, (i) if $\underline{w} f(\underline{w}-\mu-\nu)-$ $\left[\alpha+(1-\alpha) F\left(\frac{(1-\alpha) v}{\alpha}-\mu\right)\right] \geq 0$ for some $w \leqq \tilde{w}, \sigma^{m} \geq \sigma^{s}$; $^{16}$ and (ii) the worker remains with the current employer with probability $1-F(\underline{w}-\mu-\nu)$; that is, separations are inefficiently high.

This proposition shows that if specific investments are strategic complements then a minimum wage law induces the firm and the worker to train more than under spot contracting. That is, contrary to Becker's human capital theory, a minimum wage law results in more specific and general training relative to a competitive labor market. A crucial difference, however, with spot contracting is that under a minimum wage law some workers end-up unemployed. Hence, a minimum wage properly chosen increases total training, but it creates unemployment and therefore, total welfare may either increase or decrease. ${ }^{17}$

As before the fact that the firm invest in general training does not means that there is firmsponsored general training. Notice, however, that a worker gets paid at least the minimum wage, which is larger than $v\left(g^{m}\right)>\bar{v}$. This results in that there is firm-sponsored general training and that the firm and the worker share the costs and benefits of general training. Hence, the following results obtain.

Proposition 13 Because $w_{1}>\bar{v}$, there is firm sponsored-general training.

Given that our model predicts that in certain cases minimum wage laws may increase general and specific training, it is useful to take a look to the empirical evidence. The micro evidence is mixed; the studies either find a negative effect or no effect. This suggests that minimum wages may also be inducing firm-sponsored training as implied by our theory (see, Acemoglu and Pischke, 2000, for evidence and similar result).

\footnotetext{
${ }^{16}$ For instance, in the case of a uniform distribution if $\mu\left(\mathbf{s}^{m}\right)+\frac{(2 \alpha-1)}{\alpha} v\left(g^{m}\right)>0$, there is a wage such that $\sigma^{m} \geq \sigma^{s}$.

${ }^{17}$ Notice that a minimum wage law coupled with a unemployment insurance may be harmful because it decreases the worker's incentive to invest in specific training. The reason being that the cost of being unemployed is smaller with unemployment insurance.
} 


\subsubsection{Up-or-Out Contracts}

Kahn and Huberman (1988) show that up-or-out contracts can help to solve the double moral hazard problem that arises when the worker has to invest in specific training and the investment is unobservable. Waldman (1990), shows also that the same problem arises under general training and that up-or-out contracts can also help to solve the underinvestment problem in general training when there is asymmetric information. In this section, I show that an up-or-out may provide, the firm and the worker with more incentives to invest in specific and general training. On the downside, as in the minimum wage case separations are inefficiently high, but in this case there is no unemployment. The inefficient separations arises because ex-post the wage cannot be downward renegotiated.

Suppose the firm commits to pay a wage $w_{r} \geq v\left(g^{r}\right)$ to a retained worker. Hence, it is optimal to retain a worker if and only if $\mu+\nu+\eta-w_{r} \geq 0$. That is, a retention takes place if and only if $\eta \geq w_{r}-\mu-\nu$. This implies that the firm's second period expected payoff, denoted by $U_{f}^{r}\left(\sigma, w_{r}\right)$, is equal to the expected payoff under a minimum wage but for $w_{r}$ instead of $\underline{w}$; that is, $U_{f}^{r}\left(\sigma, w_{r}\right)$ is equal to equation 6 .

Whereas a worker's expected payoff, denoted by $U_{w}^{r}\left(\sigma, w_{r}\right)$, is given by

$$
\int_{\underline{w}-\mu-\nu}^{\bar{\eta}} w_{r} d F(\eta)+\int_{\underline{\eta}}^{\underline{w}-\mu-\nu} v(g) d F(\eta) .
$$

Hence, the firm's first-order conditions are the same as the ones under a minimum wage; that is, equations 8 and 9 , whereas the worker's first-order condition is different from 10 due to that a non-retained worker in this case can find a job ex-post that pays him his marginal product. Hence, the worker's first order condition is given by

$$
\begin{gathered}
\frac{\partial U_{w}^{s}(\sigma)}{\partial s_{l}}+\mu_{s_{l}}\left\{(\underline{w}-v) f(\underline{w}-\mu-\nu)-\alpha\left[1-F\left(\frac{(1-\alpha) v}{\alpha}-\mu\right)\right]\right\}+ \\
v_{g} \frac{\partial g^{r}}{\partial s_{l}}(\underline{w}-v) f(\underline{w}-\mu-\nu)- \\
v_{g} \frac{\partial g^{r}}{\partial s_{l}}\left[\alpha+(1-\alpha) F\left(\frac{(1-\alpha) v}{\alpha}-\mu\right)-F(\underline{w}-\mu-\nu)\right]-1=0
\end{gathered}
$$

Hence, the next proposition follows from lemma 11 and the worker's first-order condition. 
Proposition 14 Suppose that $U_{w}^{m}\left(\sigma, w_{r}\right)$ and $U_{f}^{m}\left(\sigma, w_{r}\right)$ are supermodular. Then, if either $\alpha \geq$ $\frac{v\left(g^{r}\right)}{w_{r}}\left(w_{r}-v\right) f\left(w_{r}-\mu-\nu\right)-\alpha\left[1-F\left(\frac{(1-\alpha) v}{\alpha}-\mu\right)\right] \geq 0$ for some $w_{r} \leqq \tilde{w}$ or $\alpha<\frac{v\left(g^{r}\right)}{w_{r}}$ and

$\left(w_{r}-v\right) f\left(w_{r}-\mu-\nu\right)-\left[\alpha+(1-\alpha) F\left(\frac{(1-\alpha) v}{\alpha}-\mu\right)\right] \geq 0$ for some $w_{r} \leqq \tilde{w}, \sigma^{r} \geq \sigma^{s}$; and (iii) the worker remains with the current employer with probability $1-F\left(w_{r}-\mu-\nu\right)$; that is, separations are inefficiently high.

The intuition is the same as the one under a minimum wage, the difference stands for the fact that a non-retained worker finds a job that pays a positive wage, while under a minimum wage a non-retained worker goes to the unemployment pool. This, on the one hand, decreases the worker's incentives to invest in specific training since the loss of not being retained is smaller, on the other hand, it increases his incentives to invest because of the complementarity between general and specific training.

So far, I have shown that under an up-or-out contract the firm invests in general and specific training, but I have not shown yet that there is firm-sponsored general training. As before Bertrandlike competition ensures that the worker gets paid

$$
w_{1}=\bar{v}+U_{f}^{r}\left(\sigma^{s}\right)-g^{r}-s_{f}^{r} \geq \bar{v} .
$$

Hence, there is firm-sponsored general training.

Proposition 15 Because $w_{1}>\bar{v}$, there is firm sponsored-general training and the firm and the worker share the returns to specific training.

\subsubsection{Promotions: Attaching Wages to Jobs}

It is known since Prendergast (1993) that the practice know as attaching wages to jobs provides incentives to invest in specific training when a worker can be promoted to a job in which the marginal product of specific training is larger. The reason being that differences in productivity allow the firm to commit to pay a higher wage in the job where specific training is larger. This plus the fact that the promotion probability increases with specific training results in larger worker's incentives 
to acquire specific training. What is key in Prendergast's result is that the firm can commit to pay a higher wage in the promotion job, here I show that a worker can, under certain conditions, be induced to acquire the efficient level of specific training when training is more productive in the promotion job. Here, I use the same logic to show that when general training is more productive in the promotion job, the firm and the worker may have more incentives to invest in specific and general training.

I assume that there are two jobs, a hard job $(h)$ and an easy job $(e)$; the marginal productivity of specific training is at least as large in the hard job; that is, $\mu_{s_{i}}^{h}(\mathbf{s}) \geq \mu_{s_{i}}^{e}(\mathbf{s}), i=f, w$, for all $\mathbf{s} \geq 0$ and the marginal productivity of general training is also at least as large in the hard job; i.e., $v_{g}^{h}(g) \geq v_{g}^{e}(g)$ for all $g \geq 0$. It is also assumed that for $\sigma=\mathbf{0}, \mu^{e}(\mathbf{0})+v^{e}(0)>\mu^{h}(\mathbf{0})+v^{h}(0)$; that is, those workers who acquire more training have a comparative advantage in the hard job and it is optimal to place an untrained worker in the easy job. It is also assumed that the firms can commit to attach a wage to each job and firm can fire the worker and the worker can quit at any time. To simplify matters I will assume that the output in the easy job is deterministic; that is, it is equal to $\mu^{e}(\mathbf{s})+v^{e}(g)$, while the output in the hard job is $\mu^{h}(\mathbf{s})+v^{h}(g)+\eta$. Finally, the firm decides whether to promote a worker or not after investments are undertaken and shock are realized.

It is easy to see that for any given training level, $\sigma$, the first-best promotion rule is to promote a worker if and only if whose output

$$
\eta \geq-\triangle \mu(\mathbf{s})-\triangle v(g)
$$

where $\triangle \mu(\mathbf{s}) \equiv \mu^{h}(\mathbf{s})-\mu^{e}(\mathbf{s})$ and $\triangle v(g) \equiv v^{h}(g)-v^{e}(g)$.

Let suppose that the firm commits in advance to pay a wage $w^{h} \geq v^{h}$ in the hard job and $w^{e} \geq v^{e}$ in the easy job. Notice that the firm would like sometimes to renegotiate the wage downwards, yet because the firm commits to attach a minimum wage to each job that is not possible. Hence, the firm only choice ex-post, when a sufficiently low productivity shock is realized, is either to let the worker go or not to promote him. Given that promotions are decided after shocks are realized, a firm will promote a worker if and only if $\mu^{h}(\mathbf{s})+v^{h}(g)+\eta-w^{h} \geq \mu^{e}(\mathbf{s})+v^{e}(g)-w^{e}$ and 
$\mu^{h}(\mathbf{s})+v^{h}(g)+\eta-w^{h} \geq 0$. If this not hold the worker remains in the easy job if $\mu^{e}(\mathbf{s})+v^{e}(g)-w^{e} \geq$ 0 , and is fired otherwise. This leads to an optimal promotion rule, conditional on profits being positive, which is to promote a worker when firm profits are at least as large when a worker is place in the hard job as when he is placed in the easy job; that is, only if

$$
\eta \geq \triangle w-\triangle \mu(\mathbf{s})-\triangle v(g)
$$

where $\triangle w \equiv w^{h}-w^{e}$.

It is worthwhile to notice that there is inefficient allocation of workers to jobs as long as $\triangle w \geq 0$. The reason being that there are is a set of states under which a worker that would have been promoted under an efficient promotion rule, is not promoted under the promotion rule that considers the wages. The reason being straightforward. Wages impose a gap on differences in productivity. ${ }^{18}$

Hence, the promotion rule is to promote if and only if

$$
\eta \geq \max \left\{\triangle w-\triangle \mu(\mathbf{s})-\triangle v(g), w^{h}-\mu^{h}(\mathbf{s})-v^{h}(g)\right\}
$$

Notice that $\triangle w-\triangle \mu(\mathbf{s})-\triangle v(g) \geq w^{h}-\mu^{h}(\mathbf{s})-v^{h}(g)$ only when $\mu^{e}(\mathbf{s})+v^{e}(g)-w^{e} \geq 0$. Thus, if $\mu^{e}(\mathbf{s})+v^{e}(g)-w^{e} \geq 0$, a worker is promoted if and only if $\eta \geq \triangle w-\triangle \mu(\mathbf{s})-\triangle v(g)$, otherwise a worker is promoted if and only if $\eta \geq w^{h}-\mu^{h}(\mathbf{s})-v^{h}(g)$.

Given this, the firm's period-2 expected payoff, denoted by $U_{w}^{a}\left(\sigma, w^{h}, w^{e}\right)$, is given by

$$
\begin{gathered}
I(\mathbf{s}) \int_{w^{h}-\mu^{h}-v^{h}}^{\bar{\eta}}\left(\mu^{h}+v^{h}+\eta-w^{h}\right) d F(\eta)+ \\
(1-I(\mathbf{s}))\left\{\int_{\triangle w-\triangle \mu-\triangle v}^{\bar{\eta}}\left(\mu^{h}+v^{h}+\eta-w^{h}\right)+\int_{\underline{\eta}}^{\Delta w-\triangle \mu-\triangle v}\left(\mu^{e}+v^{e}-w^{e}\right)\right\} d F(\eta),
\end{gathered}
$$

where $I(\mathbf{s})$ is an indicator function that takes the value 1 when $\mu^{e}(\mathbf{s})+v^{e}(g)-w^{e} \geq 0$ and 0 otherwise.

The worker's period-2 expected payoff, which is denoted by $U_{w}^{a}\left(\sigma, w^{h}, w^{e}\right)$, is given by

$$
\begin{gathered}
I(\mathbf{s})\left[\int_{w^{h}-\mu^{h}-v^{h}}^{\bar{\eta}} w^{h} d F(\eta)+\int_{\underline{\eta}}^{w^{h}-\mu^{h}-v^{h}} v^{h} d F(\eta)\right]+ \\
(1-I(\mathbf{s}))\left[\int_{\triangle w-\triangle \mu-\triangle v}^{\bar{\eta}} w^{h} d F(\eta)+\int_{\underline{\eta}}^{\triangle w-\triangle \mu-\triangle v} w^{e} d F(\eta)\right] .
\end{gathered}
$$

\footnotetext{
${ }^{18}$ See, for instance, Bernhardt and Scoones (1998), Prendergast (1993), Ricart-i-Costa (1988), and Waldman (1984) for similar reasons why firms promote too few workers.
} 
The firm's first-order conditions are then given by

$$
\begin{gathered}
I(\mathbf{s}) \mu_{s_{f}}^{h}\left(1-F\left(w^{h}-\mu^{h}-v\right)\right)+ \\
(1-I(\mathbf{s}))\left[\mu_{s_{f}}^{h}-\left(\mu_{s_{f}}^{h}-\mu_{s_{f}}^{e}\right) F(\Delta w-\Delta \mu-\triangle v)\right]-1=0,
\end{gathered}
$$

and

$$
\begin{gathered}
I(\mathbf{s}) v_{g}^{h}\left(1-F\left(w^{h}-\mu-v^{h}\right)\right)+ \\
(1-I(\mathbf{s}))\left[v_{g}^{h}-\left(v_{g}^{h}-v_{g}^{e}\right) F(\triangle w-\triangle \mu-\triangle v)\right]-1=0,
\end{gathered}
$$

whereas the worker's first order condition is given by

$$
\begin{gathered}
I(\mathbf{s})\left(w^{h}-v\right) f\left(w^{h}-\mu^{h}-v\right)\left(\mu_{s_{l}}^{h}+v_{g} \frac{\partial g}{\partial s_{l}}\right)+ \\
(1-I(\mathbf{s}))\left(\mu_{s_{l}}^{h}-\mu_{s_{l}}^{e}\right)\left(w^{h}-w^{e}\right) f(\triangle w-\triangle \mu-\triangle v)-1=0 .
\end{gathered}
$$

Notice that specific and general training are strategic complements. Furthermore, when $I(\mathbf{s})=$ 1, the first-order conditions are the same as the ones in the up-or-out rule since it is optimal to fire a non-promoted worker because profits from placing him in the easy job are negative; that is, $\mu^{e}(\mathbf{s})+v^{e}(g)-w^{e}<0$. So, the same results apply. That is, attaching wages to job may provide the firm and the worker with more incentives to train than spot contracting. Whereas when $I(\mathbf{s})=0$, it is optimal to keep a non-promoted worker in the easy job since $\mu^{e}(\mathbf{s})+v^{e}(g)-w^{e} \geq 0$.

Notice that when $\mu^{e}(\mathbf{s})+v^{e}(g)-w^{e} \geq 0$, if $v_{g}^{h}-v_{g}^{e}=0$ for all $g \geq 0$, the firm invests at the efficient level in general training. Also notice that if either $\mu_{s_{l}}^{h}-\mu_{s_{l}}^{e}=0$ for all $\mathbf{s} \geq 0$ or $w^{h}-w^{e}=0$, the worker has no incentive to invest in specific training. This is exactly the case studied by Prendergast (1993), where he shows that promotions induce specific training by the worker if and only if specific training is more productive in the hard job. Finally, notice that in either case; that is, if either $v_{g}^{h}-v_{g}^{e}=0$ for all $g \geq 0$ or $\mu_{s_{l}}^{h}-\mu_{s_{l}}^{e}=0$ for all $\mathbf{s} \geq 0$, the firm always has incentives to invest a positive amount on specific training.

This leads us to the following conclusion. 
Proposition 16 Suppose that $\mu^{e}\left(\mathbf{s}^{a}\right)+v^{e}\left(g^{a}\right)-w^{e} \geq 0$. Then (i) if $v_{g}^{h}(g)=v_{g}^{e}(g)$ for all $g \geq 0$ and $\mu_{s_{i}}^{h}(\mathbf{s})>\mu_{s_{i}}^{e}(\mathbf{s})$ for all $\mathbf{s}$ and $i=f, l, g^{a}=g^{*}>g^{s}$ and $\mathbf{s}^{a} \gtreqless \mathbf{s}^{s}$; (ii) $v_{g}^{h}(g)>v_{g}^{e}(g)$ for all $g \geq 0$ and $\mu_{s_{i}}^{h}(\mathbf{s})=\mu_{s_{i}}^{e}(\mathbf{s})$ for all $\mathbf{s}$ and $i=f, l, s_{l}^{a}=0, s_{f}^{a}>s_{f}^{s}$, and $g^{a} \gtreqless g^{s}$; and (iii) there is firm sponsored general training and the firm and the worker share the costs and benefits of specific training.

Hence, the policy of attaching wages when general training is more productive in the hard job may induce more firm-sponsored general training than spot contracting.

\section{Conclusions}

I have shown that firm sponsored general training is the rule rather than the exception in a frictionless labor market when general and specific training are neither complements nor substitutes and that delay the general training investment decision is welfare enhancing when the payoffs are supermodular. In addition, I show that long-term contracts may improve investment incentives. In fact, properly chosen long-term contracts that have some commitment built into may induce the firm to provide more general and specific training than spot contracting and may induce the worker to undertake more specific training. Hence, the model shows that Becker's human capital is not always right since firms in a competitive labor market finance worker's general training and that Acemoglu and Pischke's theory that frictions are a necessary condition for firm-sponsored general training is not correct. Hence, our model provides a very general explanation for the widely accepted fact that there is firm-sponsored general training. Finally, many of the commonly observe contractual provision that have been justified in terms of providing incentives to workers to invest in specific training, also provide the firms with incentives to invest in general and specific training.

\section{References}

[1] Acemoglu, Daron (1996): A Microfoundation for Social Increasing Returns in Human Capital Accumulation, Quarterly Journal of Economics, 111(3), 779-804. 
[2] Acemoglu, Daron and Pischke, Jorn-Steffen (1998): Why Do Firms Train?, Quarterly Journal of Economics, 111(3), 779-804.

[3] Acemoglu, Daron and Pischke, Jorn-Steffen (1999): The Structure of Wages and Investment in General Training, Journal of Political Economy.

[4] Acemoglu, Daron and Pischke, Jorn-Steffen (2000): Minimum Wages and On-the-Job Training, NBER working paper.

[5] Autor, D., (2001): Why Do Temporary Help Firms Provide Free-General Skills Training, Quarterly Journal of Economics, forthcoming.

[6] Balmaceda, F. and Sevilla, P., (2001) Firm-Sponsored General Training: The Apprenticeship Program in Chile, Working Paper, Ilades.

[7] Becker, Gary (1964): Human Capital. New York: Columbia University Press.

[8] Binmore, K. G., Ariel Rubinstein, and A. Wolinsky (1986): The Nash Bargaining Solution in Economic Modeling, Rand Journal of Economics, 17, 176-188.

[9] Bulow, Jeremy I., and Lawrence H. Summers (1986): A Theory of Dual Labor Markets with Application to Industrial Policy, Discrimination, and Keynesian Unemployment, Journal of Labor Economics, 43(1) 376-414

[10] Che, Y. and Hausch, D., (1999) Cooperative Investments and the Value of Contracting, American Economic Review, March, vol. 89, 125-147.

[11] Dow, Gregory K. (1993): Why Capital Hires Labor: A Bargaining Perspective, American Economic Review, 83(1), 118-134.

[12] Grossman, Sanford J., and Oliver D. Hart (1986): The Costs and Benefits of Own-ership: A Theory of Vertical and Lateral Integration, Journal of Political Economy, 94(4), 691-719. 
[13] Grout, Paul A. (1984): Investment and Wages in the Absence of Binding Contracts: A Nash Bargaining Approach, Economettica, March, 52(2), 449-460.

[14] Hall, Robert E., and Edward P. Lazear (1984): The Excess Sensitivity of Layoffs and Quits to Demand, Journal of Labor Economics, 2(2), 233-257.

[15] Hart, Oliver (1995): Firms, Contracts, and Financial Structure, Oxford: Clarendon Press.

[16] Hart, Oliver, and John Moore (1990): Property Rights and the Nature of the Firm, Journal of Political Economy, 98(6), 1119-1158.

$[17]$ (1994): A Theory of Debt Based on the Inalienability of Human Capital, Quarterly Journal of Economics, 109, 841-880.

[18] Kahn, C. and Huberman, G. (1988): Two Sided Uncertainty and Up-or-out Contracts, Journal of Labor Economics, VI, 423-444.

[19] Katz, E. and Ziderman, A.: Investment in General Training: The Role of Information and Labor Mobility, Economic Journal, 100, 1147-1158.

[20] Krueger, Alan B., and Lawrence H. Summers (1988): Efficiency Wages and the Inter-Industry Wage Structure, Econometrics, 56, 259-293.

[21] Klein, Benjamin, Robert G. Crawford, and Armen A. Alchian (1978): Vertical Integration, Appropriable Rents, and the Competitive Contracting Process, Journal of Law and Economics, October, 21(2), 297-326.

[22] MacLeod, W. Bentley, and James M. Malcomson (1993a): Specific Investments and Wage Profiles in Labor Market Market, European Economic Review, 37, 345-354.

[23] MacLeod, W. Bentley, and James M. Malcomson (1993b): Investments, Holdup, and the Form of Market Contracts, European Economic Review, 83(4), 811-837. 
[24] Makowski, Louis, and Joseph M. Ostroy (1995): Appropriation and Efficiency: A Revision of the First Theorem of Welfare Economics, American Economic Review, 85(4), 808-827.

[25] Milgrom, P., and Roberts, , (1990): Rationalizibility, Learning and and Equilibrium in Games with Strategic Complementarities, Econometrica, vol. 58 , 1255-1278.

[26] Milgrom, P., and Shannon, C., (1994): Monotone Comparative Statics, Econometrica, vol 62. $157-180,$.

[27] Myerson, Roger B., and Mark A. Satterthwaite (1983): Efficient Mechanisms for Bilateral Trading, Journal of Economic Theory, 28, 265-281.

[28] Noldeke, G. and Schmidt K.M. (1999), Sequential Investments and Options to Own. Rand Journal of Economics

[29] North, Douglass C., and Barry R. Weingast (1989): Constitutions and Commitment: The Evolution of Institutions Governing Public Choice in Seventeenth-Century Eng-land, Journal of Economic History, XLIX(4), 254-283.

[30] Prendergast, C. (1992) The Role of Promotions in Inducing Human Capital Acquisition, Quarterly Journal of Economics, 111(3), 523-534.

[31] Ramey, Garey, and Joel Watson (1996): Bilateral Trade and Opportunism in a Matching Market, UC San Diego Economics Discussion Paper 96-08, March.

[32] Robinson, James A. (1995): Incomplete Contracting, Capital Accumulation, and Labor Market Institutions , typescript, December.(1996)

[33] Rosenberg, Nathan (1965): Adam Smith on the Division of Labour: Two Views or One? Economics, 32( May), 127-139.

[34] Shaked, A., and J. Sutton (1984): Involuntary Unemployment as Perfect Equilibrium in a Bargaining Model, Econometrics, 52, 1351-1364. 
[35] Shleifer, Andrei, and Robert W. Vishny (1995): A Survey of Corporate Governance, Harvard Institute of Economic Research, Discussion Paper No. 1741, October.

[36] Topel, Robert (1990): Specific Capital and Unemployment: Measuring the Costs and Consequences of Job Loss, Carnegie-Rochester Conference Series on Public Policy, 33, 181-214.

[37] Waldman, M, (1990): Up-or-out Contracts: A signaling Perspective Journal of Labor Economics, vol. VIII, no 2. 230-251.

[38] Williamson, Oliver E, (1979): Transaction-Cost Economics: The Governance of Contractual Relations, Journal of Law and Economics, October, 22 (2), 233-261.

[39] Press.

[40] of Finance, XLIII(3), 567-591. 
Proof of Proposition 8: It readily follows from the first-order conditions and supermodularity (see, Milgrom and Roberts (1990)).

Proof of Proposition 9: It readily follows from the first-order conditions and supermodularity (see, Milgrom and Roberts (1990)).

Proof of Proposition 12: It readily follows from the first-order conditions and supermodularity (see, Milgrom and Roberts (1990)).

Proof of Proposition 14: It readily follows from the first-order conditions and supermodularity (see, Milgrom and Roberts (1990)).

Proof of Proposition 16: It readily follows from the first-order conditions, but for general training in case (ii). It readily follows from $\mu_{s_{i}}^{h}(\mathbf{s})=\mu_{s_{i}}^{e}(\mathbf{s})$ that $g$ is determined by the following first-order condition

$$
\left[v_{g}^{h}-\left(v_{g}^{h}-v_{g}^{e}\right) F(\triangle w-\triangle v)\right]-1=0
$$

Thus, if

$$
\left(v_{g}^{h}\left(g^{a}\right)-v_{g}^{e}\left(g^{a}\right)\right) F(\triangle w-\triangle v) \leqq v_{g}\left(g^{s}\right)\left[\alpha+(1-\alpha) F\left(\frac{(1-\alpha) v\left(g^{s}\right)}{\alpha}-\mu\left(\mathbf{s}^{s}\right)\right)\right]
$$

.That then, $g^{a} \geq g^{s}$, otherwise, $g^{a}<g^{s}$. That general training is paid by the firm follows from the arguments given in the sections above; that is, $w_{1}=\bar{v}+U_{f}^{a}\left(\sigma, w^{h}, w^{e}\right)-s_{f}^{a}-g^{a}>\bar{v}$. 